\title{
Chorioamnionitis and neonatal morbidity: current perspectives
}

This article was published in the following Dove Press journal:

Research and Reports in Neonatology

9 October 2017

Number of times this article has been viewed

\section{Gloria Mercedes Galán Henríquez \\ Fermín García-Muñoz Rodrigo}

Service of Neonatalogy, Complejo Hospital Universitario Insular Materno Infantil de Canarias, Las Palmas de Gran Canaria, Spain
Correspondence: Fermin García-Muñoz Rodrigo

Service of Neonatalogy, Complejo Hospital Universitario Insular Materno Infantil de Canarias, Avenida Marítima del Sur S/N, 35016 Las Palmas de Gran Canaria, Las Palmas, Spain

Tel/fax +34928444694

Email fgarciamu@gmail.com
Abstract: The term chorioamnionitis (CA) is commonly used to refer to different clinical or pathological conditions characterized by an infectious and/or inflammatory process that affects primarily the chorioamniotic membranes, but also the amniotic fluid, vessels of the chorionic plate, and, eventually, the umbilical cord (funisitis) and the fetus. Its incidence is higher at lower gestational ages, and the main mechanism is believed to be the ascending bacterial infection from the maternal genital tract. It can be diagnosed by clinical criteria, amniotic fluid examination for inflammatory mediators, and/or isolation of microorganisms, or by histopathological examination of the placenta. CA is an important cause of stillbirth and is related to an increased incidence of premature rupture of membranes, preterm delivery, and adverse maternal and neonatal outcomes such as early-onset neonatal sepsis and necrotizing enterocolitis. An independent causal association to other neonatal morbidities is more controversial. The heterogeneity in the diagnostic criteria and in the operative definitions for morbidity makes comparison of studies difficult, and results are inconsistent. In addition, the intensity and duration of the process are usually not considered. For all these reasons, evidence-based recommendations for the management of mother and infant under these circumstances are difficult to establish, and clinical practice varies widely.

Keywords: clinical chorioamnionitis, histological chorioamnionitis, stillbirth, prematurity, morbidity, mortality

\section{Introduction}

During the past several decades, intrauterine infection has been pointed out as one of the principal causes of premature rupture of membranes (PROM) and preterm birth,,$^{1,2}$ increasing the risk of fetal lesions, stillbirth, and morbidity and mortality after birth, including neonatal sepsis and pneumonia, respiratory distress syndrome (RDS), intraventricular hemorrhage, periventricular leucomalacia (PVL), and necrotizing enterocolitis (NEC), among others. These morbidities, in turn, have been linked to the development of chronic conditions such as bronchopulmonary dysplasia (BPD) and cerebral palsy (CP) and developmental delay. ${ }^{3,4}$ However, a direct causal relationship between $\mathrm{CA}$ and these prematurity-related morbidities is still controversial, with some studies showing no effect or even opposite results. The reason for such discrepancies could be the different definitions of CA used in the studies, and the diversity of criteria to include patients. In addition, many of these studies were retrospective, and they reported crude data without considering potential confounders.

\section{Definitions}

$\mathrm{CA}$ is an inflammatory condition of the intrauterine environment, frequently of infectious origin, that affects the chorion, amnion, or both. ${ }^{5,6}$ It is present in $0.1 \%-2 \%$ of 
all pregnancies, ${ }^{7,8}$ but in $25 \%-40 \%$ of preterm births, ${ }^{9}$ or even $40 \%-70 \%$ in cases of PROM or spontaneous labor. ${ }^{10}$ It is more frequent at the lowest gestational age $(\mathrm{GA})^{10,11}$ (Table 1), but it also complicates $1 \%-13 \%$ of term births. ${ }^{6}$ The diagnosis of CA can be made on clinical, histopathological, biochemical, or microbiological grounds, but disagreement in the criteria for diagnosis is common. A recent survey of US obstetricians found that $26 \%$ diagnose CA based only on the presence of maternal fever without taking into account any other clinical signs or symptoms. ${ }^{12}$ Frequently the inflammation is subclinical, although histological, biochemical, or microbiological findings can be present. Edwards, ${ }^{13}$ in a case series of preterm deliveries, reported a 5\%-10\% prevalence of clinical CA (CCA), while the prevalence of histological CA (HCA) was $>50 \%$. Likewise, in a personal observation (data not published) we also showed a high discrepancy between clinical and histological diagnosis of CA (Table 2).

Clinical diagnosis of CA is most frequently based on criteria adapted from Gibbs, ${ }^{14,15}$ consisting of maternal fever $>38^{\circ} \mathrm{C}$ in at least two occasions separated by 1 hour, plus two or more of the following: uterine tenderness defined as pain referred by the mother on abdominal examination in the absence of uterine contractions, leukocytosis $(>15,000$ cells/ $\left.\mathrm{mm}^{3}\right)$, maternal tachycardia $(>100 \mathrm{bpm})$, fetal tachycardia (>160 bpm), or foul smelling vaginal discharge. However, the term CCA is mainly used to express clinical suspicion before there is any laboratory or histological confirmation of the inflammation/infection, and there is growing concern about the excessive use of this term. To improve decision-making in caring for mothers and newborns, and to unify definition criteria, in 2016 an expert panel of the American College of Obstetricians and Gynecologists (ACOG) proposed the use of the term "intrauterine inflammation or infection or both" (Triple I) with the following criteria, maternal fever with one or more of the following: 1) fetal tachycardia (>160 bpm for 10 minutes or longer); 2) maternal white blood cells (WBC) count $>15,000$ in absence of corticosteroids; 3) purulent fluid from the cervical os (cloudy or yellowish thick discharge confirmed visually on speculum exam to be coming from the cervical canal); and 4) biochemical or microbiological amniotic fluid (AF) results consistent with microbial invasion of the amniotic cavity (MIAC). ${ }^{5}$ When there is an objective finding of AF infection or histopathological evidence of infection/inflammation of the placenta, membranes, or the umbilical cord, Triple I is confirmed. Otherwise, it should be categorized as "suspected." More recently, an ACOG Committee Opinion stated that "the diagnosis of suspected intraamniotic infection is made when the maternal temperature is greater than or equal to $39.0^{\circ} \mathrm{C}$ or when the maternal temperature is $38.0-38.9^{\circ} \mathrm{C}$ and one additional clinical risk factor is present," and "isolated maternal fever is defined as any maternal temperature between $38.0^{\circ} \mathrm{C}$ and $38.9^{\circ} \mathrm{C}$ with no additional risk factors present, and with or without persistent temperature elevation."16

The microbiological diagnosis is based on the isolation of the causative microorganism from culture of AF obtained by amniocentesis, but this procedure is seldom performed during labor, when symptomatology usually begins, and the results can be delayed for some days. This makes the

Table I Distribution of clinical and histological chorioamnionitis according to gestational age at delivery

\begin{tabular}{|c|c|c|c|c|c|}
\hline Gestational age (weeks) & $23-26$ & $27-30$ & $\begin{array}{l}3 I-32^{a} \\
\text { or } \\
3 I-34^{b}\end{array}$ & Total & p-value \\
\hline $\begin{array}{l}\text { Clinical chorioamnionitis }{ }^{a} \\
n / N(\%)\end{array}$ & $\begin{array}{l}653 / 1,911 \\
(34.2)\end{array}$ & $\begin{array}{l}713 / 4,498 \\
(15.9)\end{array}$ & $\begin{array}{l}|1| 4 / 1,921 \\
(5.9)\end{array}$ & $\begin{array}{l}\mathrm{I}, 480 / 8,330 \\
(17.8)\end{array}$ & $<0.001$ \\
\hline $\begin{array}{l}\text { Histological chorioamnionitis } \\
\text { n/N (\%) }\end{array}$ & $\begin{array}{l}11 / 15 \\
(73.3)\end{array}$ & $\begin{array}{l}22 / 52 \\
(42.3)\end{array}$ & $\begin{array}{l}4 / 19 \\
(21.1)\end{array}$ & $\begin{array}{l}37 / 86 \\
(43.0)\end{array}$ & 0.009 \\
\hline
\end{tabular}

Notes: "Data from García-Muñoz Rodrigo" '; N=8,330 (in this study, only patients $\leq 32$ weeks gestational age were included); ${ }^{b}$ personal observation (data not published), N=86.

Table 2 Correlation between clinical and histological chorioamnionitis in a series of 84 anatomopathological studies of placentas from gestations $\leq 34$ weeks (personal observation)

\begin{tabular}{|l|l|l|l|l|}
\cline { 3 - 5 } \multicolumn{2}{c|}{} & \multicolumn{3}{|l|}{ Histological chorioamnionitis } \\
\cline { 3 - 5 } \multicolumn{2}{c|}{} & Present & Absent \\
\hline Clinical chorioamnionitis & Positive & 7 & 2 & 9 \\
\cline { 2 - 5 } & Negative & 30 & 45 & 75 \\
\hline
\end{tabular}

Notes: ${ }^{a}$ According to Redline criteria; ${ }^{19}$ badapted from Gibbs criteria; ${ }^{14}$ sensitivity $=7 / 37=18.9 \%$; specificity $=45 / 47=95.7 \%$; positive predictive value $(\mathrm{PPV})=7 / 9=77.8 \%$; negative predictive value (NPV) $=45 / 75=60 \%$. 
microbiological diagnosis less useful for decision-making during labor. It is estimated that the frequency of positive AF cultures for bacteria in women with labor and intact membranes is $12.8 \%$, and $37.5 \%$ of them develop CCA. In contrast, in cases of preterm PROM a positive AF is found in $32.4 \%$, and CCA will develop in $29.7 \%$ of them. ${ }^{17}$ Another cause of underestimation of the rate of AF infections is that amniocentesis is less frequently carried out in women with oligohydramnios and in those admitted with labor, who usually have higher rates of infection in comparison to women admitted without labor. ${ }^{18}$

From a histological point of view, acute $\mathrm{CA}$ is characterized by diffuse infiltration of neutrophils into the chorioamniotic membranes ${ }^{19}$ as a result of intra-amniotic inflammation, although not always of bacterial origin. The process begins in the subchorionic fibrin and at the membranous choriodecidual interface, extends to the fibrous chorion and amnion, and finally necrosis of the amniotic epithelium occurs. ${ }^{20}$ Then, acute funisitis develops with involvement, in first instance, of the umbilical vein (phlebitis), which exhibits a higher expression of interleukin (IL)-8 mRNA and a pattern of gene expression suggestive of a greater predisposition to a proinflammatory response in comparison to arteries. Thereafter, polymorphonuclear (PMN) cells infiltrate arteries (arteritis), and the concentration of umbilical cord IL-6 increases, which is a marker of severity and is associated with a poorer infant prognosis. Finally, PMN cells infiltrate the Wharton's jelly (funisitis), initially as multifocal rings that subsequently coalesce as the process advances. ${ }^{21}$ The origin of the WBC present in the AF of patients with CCA is mostly fetal..$^{22} \mathrm{An}$ in-depth discussion of the histological aspects and the gradation of the inflammatory process that occurs during chorioamnionitis are beyond the scope of the present work. We refer the reader to the comprehensive chorioamnionitis grading and staging system as proposed by Redline and colleagues. ${ }^{19}$ Interestingly, a recent study showed the correlation between MMP- 8 concentration in the AF and the severity of HCA. ${ }^{23}$

\section{Pathophysiology}

The principal mechanism of CA is ascending bacterial infection after PROM, but it may also occur with intact membranes. Four stages have been described..$^{18}$ In the first one, the normal vaginal and cervical microbial flora changes and/ or pathological bacteria appear. Then (second stage) bacteria move toward the lower pole of the uterus, between the membranes and the chorion. Bacteria from the lower genital tract and their products are sensed by pattern recognition receptors, such as toll-like receptors (TLRs). Cervical dilatation and shortening (cervical incompetence) has also been associated with a higher rate of AF infections, but it is unclear whether such incompetence is the cause or consequence of the infection. ${ }^{24}$ In the third stage, bacteria invade the fetal vessels (choriovasculitis) or cross the amnion (amnionitis) into the amniotic cavity, stimulating the production of inflammatory mediators (prostaglandins and reactive oxygen radicals) and different proteases, like MMP. Finally, microorganisms reach the fetus through the respiratory or gastrointestinal tract, or through the mucous membranes (tympanic or conjunctiva). Other possible mechanisms, although less frequent, are hematogenous spread, invasion from the peritoneal cavity via the fallopian tubes, or accidental inoculation of bacteria during invasive procedures.

It is important to note that perinatal infection/inflammation, even if bacteria are not isolated, may lead to the fetal inflammatory response syndrome (FIRS), which is an endocrinological stress response with increased levels of fetal cortisol ${ }^{25}$ and fetal cellular and humoral immune activation in response to the exposure to microorganisms and/or their endotoxins, with release of cytokines and chemokines (IL-1, IL-6, IL-8, tumor necrosis factor [TNF]- $\alpha$, MMP) and upregulation of leucocyte adhesion molecules (ICAM1, E-Selectin, VCAM-1). ${ }^{26,27}$ FIRS has been defined as a rise in fetal plasma concentrations of IL- $6>11 \mathrm{pg} / \mathrm{mL} .{ }^{28}$ Patients with FIRS exhibit funisitis and chorionic vasculitis, ${ }^{29}$ and have an increased risk of neonatal sepsis, ${ }^{30} \mathrm{BPD},{ }^{31}$ and CP. ${ }^{32}$ FIRS also affects the hematopoietic system inducing the activation of the mononuclear phagocytic system with neutrophilia and neutrophil and monocyte activation. The elevation of IL- 6 stimulates the increase in the number of nucleated red cells. ${ }^{33}$ An involution of the fetal/neonatal thymus has also been observed, ${ }^{34}$ even in cases of subclinical CA. ${ }^{35}$ The grade of thymic involution may be proportional to the duration of the inflammatory process, ${ }^{36}$ and it has been associated with lesions of the brain white matter. ${ }^{37}$ In addition, the bacterial products and the inflammatory mediators released during FIRS might induce myocardial depression in the fetus. ${ }^{38}$ Given its poor ability to maintain cardiac output, this leads to hypotension and cerebral hypoperfusion, which further contribute to brain damage. ${ }^{39}$ In the skin, FIRS leads to dermatitis with increased expression of TLR-2 in epidermal keratinocytes of fetuses whose mothers had CA. ${ }^{40}$

\section{Microbiology}

The AF is sterile under normal circumstances. When microbes are detected by culture or, more recently, by molecular techniques, ${ }^{41}$ the condition has been termed MIAC. ${ }^{17}$ The 
prevalence of MIAC varies widely according to the clinical condition (term or preterm birth, intact membranes or not, with or without labor, presence of intra-uterine device, etc.). ${ }^{42}$ In a study of women with CCA at term, the detection of microorganisms by conventional cultures and/or molecular techniques was $61 \% .{ }^{43}$ In this study, intra-amniotic inflammation was defined as a concentration of IL-6 in AF $\geq 2.6 \mathrm{ng} / \mathrm{mL}$. Although $54 \%$ of the AF cases studied showed both microorganisms detection and inflammation, interestingly, $24 \%$ had inflammation without bacterial isolation, $6.5 \%$ only bacterial detection without elevation of IL-6, and, finally, 15\% neither bacteria nor inflammation. Of note, HCA was significantly more frequent in patients with microbial-associated intraamniotic inflammation than in those without intra-amniotic inflammation (70.8\% [17/24] vs 28.6\% [2/7]; $P=0.04)$.

Frequently, MIAC is polymicrobial, with two or more bacteria isolated in the AF. Genital mycoplasmas (Ureaplasma urealyticum and Mycoplasma hominis) are the most frequent agents recovered. Other microorganisms include anaerobes (Gardnerella vaginallis and Bacteroides sp.), Fusobacteria sp., aerobes (Group B Stretpococcus), and Gram-negative rods (Escherichia coli). In the rare occasions where pregnancy takes place in women with intrauterine contraceptive devices, these have been pointed out as a risk for Candida albicans infection. ${ }^{44}$

\section{Morbidity \\ Preterm birth}

Infection is probably the only pathologic process clearly related to prematurity, and the molecular mechanisms involved have been widely studied. ${ }^{45}$ It is estimated that $\sim 25 \%-40 \%$ of preterm births are related to intrauterine infections, ${ }^{2}$ and the earlier the gestational age at delivery, the higher the frequency of infection, with fetuses of 23 weeks GA colonized in up to $79 \%$ of cases in some studies. ${ }^{46}$ Furthermore, these figures may well underestimate the actual rate of intra-amniotic infections, since many of the pathogens involved, as mentioned before, do not grow in the usual cultures. The use of molecular microbiology techniques allows the isolation of DNA from bacteria in the AF of women with preterm labor in whom the conventional culture is negative. ${ }^{47}$

Preterm birth can also be triggered by changes in the normal vaginal flora (bacterial vaginosis), but although antimicrobial therapy can eradicate these bacteria, it has not proven to be useful to stop preterm birth, ${ }^{48}$ which supports its multifactorial origin. ${ }^{49} \mathrm{~A}$ mechanism of resistance of microorganisms (bacteria and fungi) to antibiotics was pos- tulated by Donlan and Costerton ${ }^{50}$ consisting in the creation of biofilms in which they are encapsulated and protected from those. This type of biofilm has been described, among others, in the urinary epithelium and in the amniotic fluid, ${ }^{51}$ but its contribution to the onset of preterm birth is unknown. On the other hand, it is also important to point out that the presence of bacteria and/or inflammatory cells in the fetal membranes does not always cause premature labor. ${ }^{52}$

The inflammatory response associated with CA leads to the rupture of membranes or preterm labor by different mechanisms, including cytokine and MMP activation causing direct rupture of membranes, triggering apoptosis of the fetal membranes cells, activation of the extrinsic pathway in response to toxins and/or cytokines (TNF- $\alpha$, IL-1ß, etc.), or activating cell mediators, such as prostaglandins, that directly induce uterine contractions. A comprehensive review of the role of inflammation and infection in preterm birth can be found in the paper by Romero et al. ${ }^{53}$

\section{Infection-related complications}

Most studies in this field have revealed a positive association between both CCA and HCA and the risk of an earlyonset neonatal sepsis (EONS), ${ }^{11,54-60}$ and this association persists after adjusting for GA, birth weight (BW), and other confounders. Fetal infection is the most advanced stage of an ascending intrauterine infection, and bacteremia have been detected in $33 \%$ of fetuses with positive AF cultures, in contrast to only $4 \%$ of fetuses with AF negative cultures. ${ }^{61}$ It is estimated that about $1.5 \%$ of very low birth weight (VLBW) infants will be affected by an EONS, while $21 \%$ of them will develop at least an episode of late-onset neonatal sepis (LONS). ${ }^{62}$ Maternal infections transmitted before or during delivery seem to be the origin of EONS, while LONS are more frequently associated to pathogens acquired from nosocomial environment. ${ }^{63-65}$ In cases of PROM, a recent systematic review has shown that maternal administration of broad-spectrum antibiotics prolongs pregnancy, and decreases the risk of chorioamnionitis and neonatal infection and, potentially, its related adverse fetal and neonatal outcomes. ${ }^{66}$ Unfortunately, even with the administration of prenatal antibiotics, several studies showed that $\mathrm{CA}$ is still related to a 2- to 10 -fold increase in the risk of EONS, ${ }^{11,59,64,65,67}$ and the risk seems to be higher when funisitis is present. ${ }^{30}$ In addition, the 7-year follow-up of children included in the ORACLE II trial found that the prescription of erythromycin for women in spontaneous preterm labor with intact membranes was associated with an increase in functional impairment among their children, and the risk of 
cerebral palsy was increased by both erythromycin and coamoxiclav, although the overall risk was low. ${ }^{68}$

Interestingly and in the opposite direction, two recent studies on CCA and HCA, respectively, have shown a reduction in the risk of LONS. ${ }^{11,60}$ The authors speculated that early stimulation of the immune system from intrauterine exposure to less virulent pathogens, rather than to the more aggressive bacteria frequently associated with EONS, or the transfer of maternal cell mediators might be the possible explanation of this phenomenon. However, this hypothesis is now being challenged by the recent finding of an association between $\mathrm{CA}$ with aberrant neonatal gut colonization and a significant increase in the risk of the combined outcome of LONS and/or death. ${ }^{69}$

Regarding the future impact of perinatal infection in these patients, it is noteworthy that numerous epidemiological studies have demonstrated an association between systemic inflammation in the fetus/newborn of intrauterine or postnatal origin and brain damage, ${ }^{70-74}$ which will be discussed in more detail in the following section.

\section{Necrotizing enterocolitis}

NEC is less common than other complications in the preterm newborn, but remains a relevant problem for the VLBW infant due to its potential severity and its adverse consequences in both the short and long term. Although believed to be multifactorial, the exact mechanism of its development is not fully understood, and its incidence has not changed substantially over time. ${ }^{75}$ It affects around $7 \%$ of neonates with BW 500-1,500 g, and 11.5\% in the subgroup of $\leq 750 \mathrm{~g}^{76}$ Mortality varies between $20 \%$ and $30 \%$, and it is higher in patients requiring surgery. ${ }^{77,78}$ Evidence relating CA to NEC is not consistent, but several studies, summarized in the meta-analysis of Been et al, ${ }^{79}$ support that CCA is significantly associated with NEC (odds ratio [OR] 1.24, 95\% CI 1.01-1.52; $P=0.04$ ), as well as HCA with fetal involvement (OR, 3.29; 95\% CI, 1.87-5.78; $P \leq 0.001)$. In addition, a recent study showed that, after adjusting for GA, a high grade of fetal inflammation was significantly associated with chronic lung disease and necrotizing enterocolitis. ${ }^{80}$ Of note, in the context of PROM and subclinical infection, it is well known that maternal antibiotic therapy might lessen infectious morbidity and delay labor, but co-amoxiclav should be avoided because of the increased risk of NEC (risk ratio [RR] 4.60, 95\% CI 1.98-10.72). ${ }^{81}$

NEC basically consists of ischemic necrosis of the intestinal mucosa with important inflammation and invasion by gasforming microorganisms, which can dissect the muscular layer of the mucosa and reach the portal venous system. However, the clinical spectrum varies from this "classic" form to focal intestinal perforations with less inflammatory component that probably have a different etiopathogenesis. ${ }^{82}$ The lack of consistent diagnostic criteria makes it difficult to compare results among studies. However, the gradation system of Bell et al in $1978,{ }^{83}$ with some subsequent adaptations ${ }^{84}$ despite some possible limitations, has been very useful for decisionmaking with patients and to compare results between different centers. NEC is the first cause of short bowel syndrome in infancy. Apart from the potentially devastating local effects, the intense inflammatory processes that accompany its course have systemic repercussion, with damage to distant organs such as the brain. This adds to an increased risk of neurodevelopment impairment in this already vulnerable group of patients. ${ }^{85,86}$ Martin et al recently reported an increased risk of neurodevelopmental dysfunction and microcephaly in patients with surgical NEC, especially when associated with late bacteremia. ${ }^{87}$ Finally, a systematic review aimed at characterizing the neurodevelopment of extremely-low-birth-weight infants $(<1,000 \mathrm{~g})$ with NEC and the possible relationship between NEC stage and the neurosensory outcomes found 10 studies comparing patients of the same GA with and without NEC and an average follow-up of 20 months. ${ }^{88}$ Globally, $45 \%$ of infants with NEC had some form of neurodevelopment impairment. Table 3 summarizes the main results of this study.

\section{Respiratory morbidity}

Again, the relationship between $\mathrm{CA}$ and respiratory morbidity in the preterm infants, although extensively studied, remains controversial. Fetuses make breathing movements in utero and may aspirate AF that reaches the distal airway and the alveoli. In Watterberg et al's study, ${ }^{89}$ infants prenatally exposed to HCA had greater concentrations of IL-1 $\beta$ in tracheal aspirates from the first day of intubation and exhibited

Table 3 Risk of neurodevelopment and neurosensorial impairment in VLBW infants with NEC in comparison to patients of the same GA without NEC

\begin{tabular}{llll}
\hline Result & OR & $\mathbf{9 5 \% ~ C l}$ & P-value \\
\hline Altered neurodevelopment & $\mathrm{I} .6$ & $(\mathrm{I} .3-2.0)$ & $<0.00 \mathrm{I}$ \\
& $2.3^{\mathrm{a}}$ & $(\mathrm{I} .5-3.6)^{\mathrm{a}}$ & $<0.00 \mathrm{I}^{\mathrm{a}}$ \\
Cerebral palsy & $\mathrm{I} .5$ & $(\mathrm{I} .2-2.0)$ & $0.00 \mathrm{I}$ \\
Visual impairment & 2.3 & $(\mathrm{I} .0-5 . \mathrm{I})$ & 0.04 \\
Cognitive impairment & $\mathrm{I} .7$ & $(\mathrm{I} .4-2.2)$ & $<0.00 \mathrm{I}$ \\
Psychomotor impairment & $\mathrm{I} .7$ & $(\mathrm{I} .3-2.2)$ & $<0.00 \mathrm{I}$ \\
\hline
\end{tabular}

Note: Data from Rees et al; ${ }^{88}$ ain patients with Bell's stage 3.

Abbreviations: VLBW, very low birth weight; NEC, necrotizing enterocolitis; GA, gestational age; OR, odds ratio. 
less respiratory distréss syndrome (RDS), but thereafter they developed more frequently BPD. In animal experimentation, a maturative effect of intra-amniotic administration of IL- $1 \alpha$ has also been observed, ${ }^{90}$ with increased expression of surfactant proteins A and B, and lipids. Likewise, Ghezzi et al studied the exposure of fetuses to subclinical intrauterine inflammation and found elevated concentrations of IL-8 in AF of mothers of 24-28 weeks who subsequently developed BPD. ${ }^{91}$ All these studies support the hypothesis that HCA could stimulate lung maturation, reducing the incidence of acute RDS but, at the same time, increasing the lung susceptibility to postnatal damage, which finally leads to BPD. The maturational effect of prenatal inflammation may be accompanied not only by structural changes in the lungs, ${ }^{92}$ but also by an alteration in the response to exogenous surfactant and the need of prolonged mechanical ventilation. ${ }^{93}$ Nevertheless, it is important to remember that prematurity itself is characterized by lungs with a smaller number of alveoli, a slow microvascular development, and thickening of the arteriolar walls. Other mechanisms, such as a neonatal leukemoid reaction induced by $\mathrm{CA}$, have also been suggested as important risk factor for BDP. ${ }^{94,95}$ In contrast to $\mathrm{HCA}$, Alexander et al reported an increased incidence of RDS among preterm babies exposed to CCA. Of note, many of these studies were conducted prior to the widespread use of prenatal corticosteroids for fetal lung maturation, exogenous surfactant administration, and/or noninvasive ventilation, which are currently considered standard practices with proven benefit for patients and improved respiratory outcomes. ${ }^{96}$ In summary, although unadjusted and adjusted analyses showed that CA was significantly associated with BPD, a recent systematic review and meta-analysis by Hartling et al concluded that CA cannot be definitively considered a risk factor for BPD due to the strong evidence of publication bias with potential overestimation of the association between them ${ }^{97}$ (Table 4).

\section{Patent ductus arteriosus}

The relationship between the exposure to CCA or HCA and patent ductus arteriosus (PDA) is again conflicting. Most studies seem to show a positive relationship when crude data are analyzed. ${ }^{98}$ In contrast, in our large multicenter study, after adjusting for confounders, we found that the risk of PDA was significantly lower among infants exposed to CCA (adjusted OR $0.831,95 \%$ CI $0.711-0.971 ; P=0.02) .{ }^{11}$ However, a recent meta-regression analysis by Behbodi et $\mathrm{al}^{99}$ concluded that the differences in GA or BW between the CA-exposed and nonexposed groups were significantly correlated with the effect size of the association between CA and PDA and, consequently, CA appears not to be a risk factor for PDA in preterm infants (Table 4).

\section{Brain injury}

In 1955, Eastman Eastman and Deleon first observed that intrapartum maternal fever increased seven times the risk of CP. ${ }^{100}$ Subsequently, this same phenomenon was observed in VLBW infants born to mothers with CA. ${ }^{101}$ Since then, numerous studies have tried to delve into the mechanisms by which the infection/inflammation produces brain damage. However, neither clinical trials nor large meta-analyses have yielded homogeneous results. ${ }^{102}$ Although germinal matrix $\mathrm{HIV}$ is the most frequently acquired brain lesion in VLBW infants diagnosed by cerebral ultrasound (CUS), evaluation at discharge with magnetic resonance imaging (MRI) has shown that brain white matter damage (WMD) is much more common, affecting at least $50 \%$ of very preterm infants. ${ }^{103,104}$ This injury is probably the leading cause of deficits observed in $\sim 90 \%$ of survivors, including CP (5\%-10\%) and cognitive, attention, and behavioral disorders (about 50\%). ${ }^{105,106}$ Although other lesions, such as periventricular hemorrhagic infarction, post-hemorrhagic dilatation, or cerebellar lesion, may coexist, WMD seems to be the predominant one. ${ }^{107}$ Two major factors are involved in the etiology of WMD, ischemia and infection/inflammation, along with the marked vulnerability of oligodendroglia to oxidative stress. The cerebral vasculature of the preterm infant is characterized by "borderline" zones, ${ }^{108}$ where cerebral blood flow (CBF) is more vulnerable to decreases in blood pressure. In addition, sick preterm infants have a lower capacity for CBF autoregulation, making the brain more susceptible to diffuse ischemic damage. ${ }^{109,110}$ Hypoxia-ischemia can lead to cytokine elevation even in the absence of infection. ${ }^{111}$ Infection causes damage or death of oligodendroglial precursors, ${ }^{107}$ mediated by proinflammatory cytokines, especially interferon- $\gamma$ and TNF- $\alpha,{ }^{112}$ and by the activation of the microglia in the immature brain white matter, with the subsequent production of free radicals. ${ }^{113}$

Some clinical and epidemiological studies have shown an association between maternal-fetal infection and PVL (detected by CUS), CP, ${ }^{114,115}$ and/or sensorineural involvement (visual impairment, hearing loss, and/or speech delay) during follow-up. ${ }^{116,117}$ Among extremely low GA neonates ( $<27$ weeks), Pappas et al showed that infants exposed to CA had a lower GA, and that HCA alone not, but HCA plus CCA increased the risk of cognitive impairment at 18-22 months' corrected age (adjusted OR 2.00, 95\% CI 1.10-3.64). ${ }^{118}$ 


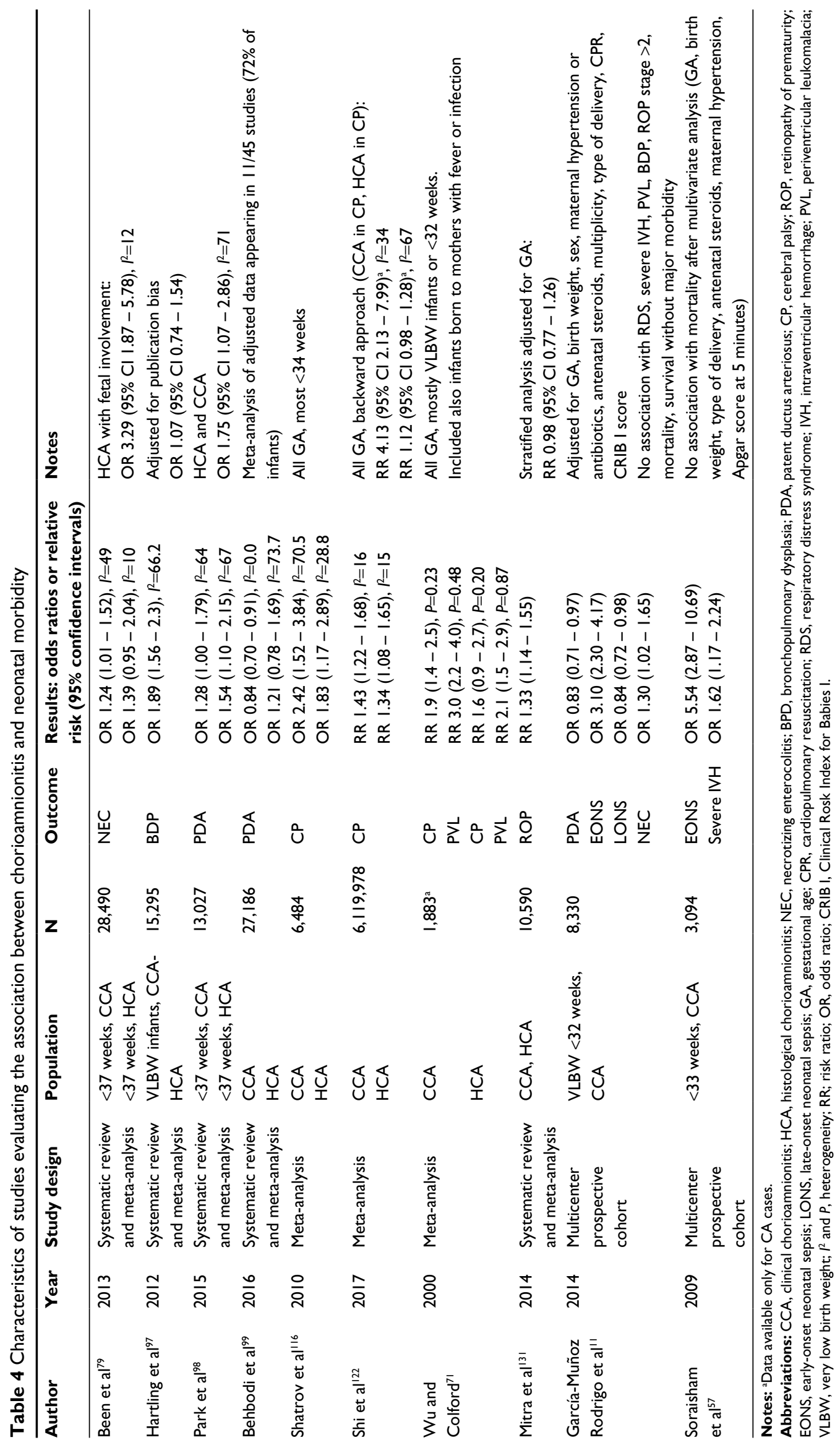


However, as stated before, CA is strongly associated with preterm birth and, after adjusting for GA, the association between CA and PVL decreases or disappears. For this reason, a causal relationship between them has been questioned by some. ${ }^{119}$ Yliloki et al recently reported the lack of association between CCA and neurodevelopmental problems in very preterm infants. ${ }^{120}$ In contrast, HCA was associated with a slightly less optimal performance at 5 years of age, although, in their opinion, further studies are needed to verify the clinical significance of these findings. Previously, in a systematic review by the same group that included 84 original papers, they concluded that the majority of the studies did not support the hypothesis that CA poses a direct risk on the central nervous system of preterm infants. ${ }^{121}$ Similar conclusions seem to be derived from most recent reviews. ${ }^{122,123}$

An additional problem when evaluating the relationship between CA and WMD is that most of the initial studies, especially epidemiological ones, referred to cystic PVL, which is currently estimated to contribute to less than $10 \%$ of WMD cases. Modern technologies could provide new insight into the subject. In a recent study, magnetic resonance spectroscopy in healthy term newborns exposed to maternal CA showed evidence of occult neuroinflammation, and the author suggested that this finding might be associated to neurodevelopmental outcomes at 12 months. ${ }^{124}$ Another study with $\mathrm{MRI}$ in patients exposed to CA revealed long-term alterations in brain morphology in areas related to cognitive and motor functions, leading to psychiatric and neurodevelopmental disorders, although this study was limited by the small sample size. ${ }^{125}$ In summary, to date, the relationship between CA and neurodevelopmental outcomes is not completely understood, and the studies' results might be influenced by variables that covariate with or mediate the effect of the other.

\section{Mortality}

Perinatal mortality related to maternal $\mathrm{CA}$ has been addressed in several studies, but results are still conflicting. Elimian et al found that HCA was independently associated with neonatal death, although in exposed infants the administration of antenatal steroids significantly reduced morbidity and mortality. ${ }^{126}$ The risk of neonatal mortality seems to be higher when there is evidence of fetal inflammation (funisitis and/or fetal vessel angiitis). ${ }^{127}$ In a population-based study of full-term infants born in the United States during 2008, the prevalence of CCA was 9.7 per 1,000 live births, and the neonatal mortality rate was higher among exposed infants (OR 1.72, 95\% CI 1.20-2.45). ${ }^{7}$ In contrast, several studies on CCA or HCA in VLBW infants, after correcting for confounders, showed no effect on mortality ${ }^{11,60}$ or, on the contrary, they showed a protective effect. ${ }^{128,129}$ In the study by Lahra et al, both HCA and a histological fetal response to $\mathrm{CA}$ were observed to be more common in preterm survivors of the neonatal period. ${ }^{130}$ In the same direction, Pappas et al found that HCA was associated with a reduced risk of death or neurodevelopmental impairment (adjusted OR 0.72, 95\% CI 0.56-0.93]). ${ }^{118}$

\section{Conclusion}

Although some experimental evidence in animal models and the results of human research have demonstrated or suggest adverse effects of intra-amniotic infection/inflammation in the fetus/newborn, controversy still persists regarding a direct relationship between maternal CA and most of the neonatal outcomes studied. Table 4 summarizes the most relevant systematic reviews and meta-analyses. To date, the association between CA and preterm birth and EONS and NEC seems to be clear. Prematurity itself is a major risk factor for many different morbidities known to be of multifactorial origin. Prenatal infection/inflammation or both could have a modulating effect over them in both directions, sometimes increasing the final risk while sometimes reducing it, as it seems to be the case for RDS, for instance. The heterogeneity of the studies and the variety of clinical situations and management of patients in a changing field of knowledge (prenatal steroids, maternal antibiotics, postnatal surfactant administration, noninvasive ventilator support, etc.) precludes establishing a definitive relationship between $\mathrm{CA}$ and a particular morbidity. In the opinion of the authors, as new diagnostic tools develop and as new strategies of patient management are implemented, new associations could be detected or, on the contrary, some current beliefs will vanish.

\section{Disclosure}

The authors report no conflicts of interest in this work.

\section{References}

1. Newton ER. Chorioamnionitis and intraamniotic infection. Clin Obstet Gynecol. 1993;36:795-808.

2. Goldenberg RL, Hauth JC, Andrews WW. Intrauterine infection and preterm delivery. $N$ Engl J Med. 2000;342:1500-1507.

3. Hagberg H, Wennerholm UB, Savman K. Sequelae of chorioamnionitis. Curr Opin Infect Dis. 2002;15:301-306.

4. Bracci R, Buonocore G. Chorioamnionitis: a risk factor for fetal and neonatal morbidity Biol Neonate. 2003;83:85-96.

5. Higgins RD, Saade G, Polin RA, et al. Evaluation and management of women and newborns with a maternal diagnosis of chorioamnionitis: summary of a workshop. Obstet Gynecol. 2016;127(3):426-436.

6. Tita A, Andrews W. Diagnosis and management of clinical chorioamnionitis. Clin Perinatol. 2010;37(2):339-354.

7. Malloy MH. Chorioamnionitis: epidemiology of newborn management and outcome United States 2008. J Perinatol. 2014;34(8):611-615. 
8. Al-Ostad G, Kezouh A, Spence AR, Abenhaim HA. Incidence and risk factors of sepsis mortality in labor, delivery and after birth: population based study in the USA. J Obstet Gynaecol Res. 2015;41(8): 1201-1206.

9. Muglia LJ, Katz M. The enigma of spontaneous preterm birth. NEngl JMed. 2010;362:529-535.

10. Yoon BH, Romero R, Moon JB, et al. Clinical significance of intraamniotic inflammation in patients with preterm labor and intact membranes. Am J Obstet Gynecol. 2001;185(5):1130-1136.

11. García-Muñoz Rodrigo F, Galán Henríquez G, Figueras Aloy J, GarcíaAlix Pérez A. Outcomes of very-low-birth-weight infants exposed to maternal clinical chorioamnionitis: a multicenter study. Neonatology. 2014;106(3):229-234.

12. Greenberg MB, Anderson BL, Schulkin J, Norton ME, Aziz N. A first look at chorioamnionitis management practice variation among US obstetricians. Infect Dis Obstet Gynecol. 2012;2012(2):628362-628369.

13. Edwards RK. Chorioamnionitis and labor. Obstet Gynecol Clin North Am. 2005;32:287-296.

14. Gibbs RS, Duff P. Progress in pathogenesis and management of clinical intraamniotic infection. Am J Obstet Gynecol. 1991;164: 1317-1326.

15. Thomas W, Speer CP. Chorioamnionitis: important risk factor or innocent bystander for neonatal outcome? Neonatology. 2011;99(3):177-187.

16. Committee on Obstetric Practice. Committee Opinion No. 712: Intrapartum Management of Intraamniotic Infection.. Obstet Gynecol. 2017;130(2):e95-e101.

17. Gonçalves LF, Chaiworapongsa T, Romero R. Intrauterine infection and prematurity. Ment Retard Dev Disabil Res Rev. 2002;8(1):3-13.

18. Romero R, Mazor M. Infection in preterm labor. Clin Obstet Gynecol. 1988;31:553-584.

19. Redline RW, Faye-Petersen O, Heller D, Qureshi F, Savell V, Vogler C; Society for Pediatric Pathology, Perinatal Section, Amniotic Fluid Infection Nosology Committee. Amniotic infection syndrome: nosology and reproducibility of placental reaction patterns. Pediatr Dev Pathol. 2003;6:435-448.

20. Redline RW. Classification of placental lesions. Am J Obstet Gynecol. 2015;213(4 Suppl):S21-28.

21. Kim CJ, Yoon BH, Kim M, Park JO, Cho SY, Chi JG. Histo-topographic distribution of acute inflammation of the human umbilical cord. Pathol Int. 2001;51(11):861-865.

22. Sampson JE, Theve RP, Blatman RN, et al. Fetal origin of amniotic fluid polymorphonuclear leukocytes. Am J Obstet Gynecol. 1997;176(1 Pt 1):77-81.

23. Kim SM, Romero R, Park JW, Oh KJ, Jun JK, Yoon BH. The relationship between the intensity of intra-amniotic inflammation and the presence and severity of acute histologic chorioamnionitis in preterm gestation. J Matern Fetal Neonatal Med. 2015;28(13):1500-1509.

24. Hassan S, Romero R, Hendler I, et al. A sonographic short cervix as the only clinical manifestation of intra-amniotic infection. J Perinat Med. 2006;34(1):13-19.

25. Yoon BH, Romero R, Jun JK, et al. An increase in fetal plasma cortisol but not dehydroepiandrosterone sulfate is followed by the onset of preterm labor in patients with preterm premature rupture of the membranes. Am J Obstet Gynecol. 1998;179(5):1107-1114.

26. Newnham JP, Moss TJ, Kramer BW, Nitsos I, Ikegami M, Jobe $\mathrm{AH}$. The fetal maturational and inflammatory responses to different routes of endotoxin infusion in sheep. Am J Obstet Gynecol. 2002;186(5):1062-1068.

27. Arad I, Ergaz Z. The fetal inflammatory response syndrome and associated infant morbidity. Isr Med Assoc J. 2004;6(12):766-769.

28. Gomez R, Romero R, Ghezzi F, Yoon BH, Mazor M, Berry SM. The fetal inflammatory response syndrome. Am J Obstet Gynecol. 1998;179(1):194-202.

29. Pacora P, Chaiworapongsa T, Maymon E, et al. Funisitis and chorionic vasculitis: the histological counterpart of the fetal inflammatory response syndrome. J Matern Fetal Neonatal Med. 2002;11(1):18-25.
30. Yoon BH, Romero R, Park JS, et al. The relationship among inflammatory lesions of the umbilical cord (funisitis), umbilical cord plasma interleukin 6 concentration, amniotic fluid infection, and neonatal sepsis. Am J Obstet Gynecol. 2000;183(5):1124-1129.

31. Yoon BH, Romero R, Kim KS, et al. A systemic fetal inflammatory response and the development of bronchopulmonary dysplasia. Am J Obstet Gynecol. 1999;181(4):773-779.

32. Yoon BH, Romero R, Park JS, et al. Fetal exposure to an intra-amniotic inflammation and the development of cerebral palsy at the age of three years. Am J Obstet Gynecol. 2000;182(3):675-681.

33. Ferber A, Minior VK, Bornstein E, Divon MY. Fetal "nonreassuring status" is associated with elevation of nucleated red blood cell counts and interleukin-6. Am J Obstet Gynecol. 2005;192(5):1427-1429.

34. Toti P, De Felice C, Stumpo M, et al. Acute thymic involution in fetuses and neonates with chorioamnionitis. Hum Pathol. 2000; 31(9):1121-1128.

35. De Felice C, Toti P, Santopietro R, Stumpo M, Pecciarini L, Bagnoli F. Small thymus in very low birth weight infants born to mothers with subclinical chorioamnionitis. J Pediatr. 1999;135(3):384-386.

36. Glavina-Durdov M, Springer O, Capkun V, Saratlija-Novaković Z, Rozić D, Barle M. The grade of acute thymus involution in neonates correlates with the duration of acute illness and with the percentage of lymphocytes in peripheral blood smear. Pathological study. Biol Neonate. 2003;83(4):229-234.

37. Kuban JD, Allred EN, Leviton A. Thymus involution and cerebral white matter damage in extremely low gestational age neonates. Biol Neonate. 2006;90(4):252-257.

38. Court O, Kumar A, Parrillo JE, Kumar A. Clinical review: myocardial depression in sepsis and septic shock. Crit Care. 2002;6(6):500-508.

39. Garnier Y, Coumans AB, Jensen A, Hasaart TH, Berger R. Infectionrelated perinatal brain injury: the pathogenic role of impaired fetal cardiovascular control. J Soc Gynecol Investig. 2003;10(8):450-459.

40. Kim YM, Romero R, Chaiworapongsa T, Espinoza J, Mor G, Kim CJ Dermatitis as a component of the fetal inflammatory response syndrome is associated with activation of Toll-like receptors in epidermal keratinocytes. Histopathology. 2006;49(5):506-514.

41. Digiulio DB, Romero R, Amogan HP, et al. Microbial prevalence, diversity and abundance in amniotic fluid during preterm labor: a molecular and culture-based investigation. PLoS One. 2008;3(8):e3056.

42. Kim CJ, Romero R, Chaemsaithong P, Chaiyasit N, Yoon BH, Kim YM Acute chorioamnionitis and funisitis: definition, pathologic features, and clinical significance. Am J Obstet Gynecol. 2015;213(4 Suppl):S29-S52.

43. Romero R, Miranda J, Kusanovic JP, et al. Clinical chorioamnionitis at term I: microbiology of the amniotic cavity using cultivation and molecular techniques. J Perinat Med. 2015;43(1):19-36.

44. Kim SK, Romero R, Kusanovic JP, et al. The prognosis of pregnancy conceived despite the presence of an intrauterine device (IUD). J Perinatal Med. 2010;38(1):45-53.

45. Romero R, Mazor M, Munoz H, Gomez R, Galasso M, Sherer DM. The preterm labor syndrome. Ann N Y Acad Sci. 1994;734:414-429.

46. Watts DH, Krohn MA, Hillier SL, Eschenbach DA. The association of occult amniotic fluid infection with gestational age and neonatal outcome among women in preterm labor. Obstet Gynecol. 1992;79: 351-357.

47. Gardella C, Riley DE, Hitti J, Agnew K, Krieger JN, Eschenbach D. Identification and sequencing of bacterial rDNAs in culturenegative amniotic fluid from women in premature labor. $\mathrm{Am} \mathrm{J}$ Perinatol. 2004;21(6):319-323.

48. Nygren P, Fu R, Freeman M, Bougatsos C, Klebanoff M, Guise JM. Evidence on the benefits and harms of screening and treating pregnant women who are asymptomatic for bacterial vaginosis: an update review for the U.S. Preventive Services Task Force. Ann Intern Med. 2008;148:220-233.

49. Menon R, Taylor RN, Fortunato SJ. Chorioamnionitis - a complex pathophysiologic syndrome. Placenta. 2010;31(2):113-120.

50. Donlan RM, Costerton JW. Biofilms: survival mechanisms of clinically relevant microorganisms. Clin Microbiol Rev. 2002;15:167-193. 
51. Romero R, Schaudinn C, Kusanovic JP, et al. Detection of a microbial biofilm in intraamniotic infection. Am J Obstet Gynecol. 2008;198(1):135.e1-135.e5.

52. Steel JH, Malatos S, Kennea N, et al. Bacteria and inflammatory cells in fetal membranes do not always cause preterm labor. Pediatr Res. 2005;57(3):404-411.

53. Romero R, Espinoza J, Gonçalves LF, Kusanovic JP, Friel L, Hassan S. The role of inflammation and infection in preterm birth. Semin Reprod Med. 2007;25(1):21-39.

54. Alexander JM, Gilstrap LC, Cox SM, McIntire DM, Leveno KJ. Clinical chorioamnionitis and the prognosis for very low birth weight infants. Obstet Gynecol. 1998;91:725-729.

55. Dempsey E, Chen MF, Kokottis T, Vallerand D, Usher R. Outcome of neonates less than 30 weeks gestation with histologic chorioamnionitis. Am J Perinatol. 2005;22:155-159.

56. Andrews WW, Goldenberg RL, Faye-Petersen O, Cliver S, Goepfert AR, Hauth JC. The Alabama Preterm Birth study: polymorphonuclear and mononuclear cell placental infiltrations, other markers of inflammation, and outcomes in 23- to 32-week preterm newborn infants. $\mathrm{Am}$ J Obstet Gynecol. 2006;195:803-808.

57. Soraisham AS, Singhal N, McMillan DD, Sauve RS, Lee SK; Canadian Neonatal Network. A multicenter study on the clinical outcome of chorioamnionitis in preterm infants. Am J Obstet Gynecol. 2009;200:372. e1-372.e6.

58. Botet F, Figueras J, Carbonell-Estrany X, Arca G; Castrillo Study Group. Effect of maternal clinical chorioamnionitis on neonatal morbidity in very-low birthweight infants: a case-control study. J Perinat Med. 2010;38:269-273.

59. García-Muñoz Rodrigo F, Galán Henríquez GM, Gómez Ospina C. Morbidity and mortality among very-low-birth-weight infants born to mothers with clinical chorioamnionitis. Pediatr Neonatol. 2014;55(5):381-386.

60. Strunk T, Doherty D, Jacques A, et al. Histologic chorioamnionitis is associated with reduced risk of late-onset sepsis in preterm infants. Pediatrics. 2012;129:e134-e141.

61. Carroll SG, Papaioannou S, Ntumazah IL, Philpott-Howard J, Nicolaides KH. Lower genital tract swabs in the prediction of intrauterine infection in preterm prelabour rupture of the membranes. Br J Obstet Gynecol. 1996;103(1):54-59.

62. Stoll BJ, Hansen N. Infections in VLBW infants: studies from the NICHD Neonatal Research Network. Semin Perinatol. 2003;27: 293-301.

63. Thomas W, Speer CP. Chorioamnionitis: important risk factor or innocent bystander for neonatal outcome? Neonatology. 2011;99(3): 177-187.

64. Pugni L, Pietrasanta C, Acaia B, et al. Chorioamnionitis and neonatal outcome in preterm infants: a clinical overview. J Matern Fetal Neonatal Med. 2016;29(9):1525-1529.

65. Ofman G, Vasco N, Cantey JB. Risk of early-onset sepsis following preterm, prolonged rupture of membranes with or without Chorioamnionitis. Am J Perinatol. 2016;33(4):339-342.

66. Kenyon S, Boulvain M, Neilson JP. Antibiotics for preterm rupture of membranes. Cochrane Database Syst Rev. 2013;(12): CD001058.

67. Liu Z, Tang Z, Li J, Yang Y. Effects of placental inflammation on neonatal outcome in preterm infants. Pediatr Neonatol. 2014;55(1):35-40.

68. Kenyon S, Pike K, Jones DR, et al. Childhood outcomes after prescription of antibiotics to pregnant women with spontaneous preterm labour: 7-year follow-up of the ORACLE II trial. Lancet. 2008;372(9646): 1319-1327.

69. Puri K, Taft DH, Ambalavanan N, Schibler KR, Morrow AL, Kallapur SG. Association of chorioamnionitis with aberrant neonatal gut colonization and adverse clinical outcomes. PLOS ONE. 2016;11(9):e0162734

70. Volpe JJ. Postnatal sepsis, necrotizing entercolitis, and the critical role of systemic inflammation in white matter injury in premature infants. J Pediatr. 2008;153:160-163.
71. Wu YW, Colford JM. Chorioamnionitis as a risk factor for cerebral palsy. A meta-analysis. JAMA. 2000;284:1417-1424.

72. Shah DK, Doyle LW, Anderson PJ, et al. Adverse neurodevelopment in preterm infants with postnatal sepsis or necrotizing enterocolitis is mediated by white matter abnormalities on magnetic resonance imaging at term. J Pediatr. 2008;153:170-175.

73. Chau V, Poskitt KJ, McFadden DE, et al. Effect of chorioamnionitis on brain development and injury in premature newborns. Ann Neurol. 2009;66:155-164.

74. Leviton A, Allred EN, Kuban KC, et al. Microbiologic and histologic characteristics of the extremely preterm infant's placenta predict white matter damage and later cerebral palsy. the ELGAN study. Pediatr Res. 2010;67:95-101.

75. Obladen M. Necrotizing enterocolitis -150 years of fruitless search for the cause. Neonatology. 2009;96:203-210.

76. Holman RC, Stoll BJ, Curns AT, Yorita KL, Steiner CA, Schonberger LB. Necrotising enterocolitis hospitalisations among neonates in the United States. Paediatr Perinat Epidemiol. 2006;20:498-506.

77. Horbar JD, Carpenter JH, Badger GJ, et al. Mortality and neonatal morbidity among infants 501 to 1500 grams from 2000 to 2009. Pediatrics. 2012;129(6):1019-1026.

78. Fitzgibbons SC, Ching Y, Yu D, et al. Mortality of necrotizing enterocolitis expressed by birth weight categories. J Pediatr Surg. 2009;44: 1072-1075.

79. Been JV, Lievense S, Zimmermann LJ, Kramer BW, Wolfs TGA. Chorioamnionitis as a risk factor for necrotizing enterocolitis: a systematic review and meta-analysis. J Pediatr. 2013;162(2): 236-242.

80. Yamada N, Sato Y, Moriguchi-Goto S, et al. Histological severity of fetal inflammation is useful in predicting neonatal outcome. Placenta. 2015;36(12):1490-1493.

81. Kenyon S, Boulvain M, Neilson J. Antibiotics for preterm rupture of membranes. Cochrane Database Syst Rev. 2003;(2):CD001058.

82. Neu J, Walker WA. Necrotizing enterocolitis. N Engl J Med. 2011;364: 255-264.

83. Bell MJ, Ternberg JL, Feigin RD, et al. Neonatal necrotizing enterocolitis: therapeutic decisions based upon clinical staging. Ann Surg. 1978;187:1-7.

84. Walsh MC, Kliegman RM. Necrotizing enterocolitis: treatment based on staging criteria. Pediatr Clin North Am. 1986;33:179-201.

85. Salhab WA, Perlman JM, Silver L, Sue Broyles R. Necrotizing enterocolitis and neurodevelopmental outcome in extremely low birth weight infants $<1000$ g. J Perinatol. 2004;24:534-540.

86. Hintz SR, Kendrick DE, Stoll BJ, et al. Neurodevelopmental and growth outcomes of extremely low birth weight infants after necrotizing enterocolitis. Pediatrics. 2005;115:696-703.

87. Martin CR, Dammann O, Allred EN, et al. Neurodevelopment of extremely preterm infants who had necrotizing enterocolitis with or without late bacteremia. J Pediatr. 2010;157(5):751-756.

88. Rees CM, Pierro A, Eaton S. Neurodevelopmental outcomes of neonates with medically and surgically treated necrotizing enterocolitis. Arch Dis Child Fetal Neonatal Ed. 2007;92:F193-198.

89. Watterberg KL, Demers LM, Scott SM, Murphy S. Chorioamnionitis and early lung inflammation in infants in whom bronchopulmonary dysplasia develops. Pediatrics. 1996;97(2):210-215.

90. Bry K, Lappalainen U, Hallman M. Intraamniotic interleukin-1 accelerates surfactant protein synthesis in fetal rabbits and improves lung stability after premature birth. J Clin Invest. 1997;99(12): 2992-2999.

91. Ghezzi F, Gomez R, Romero R, et al. Elevated interleukin-8 concentrations in amniotic fluid of mothers whose neonates subsequently develop bronchopulmonary dysplasia. Eur J Obstet Gynecol Reprod Biol. 1998;78(1):5-10.

92. Kramer BW, Ladenburger A, Kunzmann S, et al. Intravenous lipopolysaccharide-induced pulmonary maturation and structural changes in fetal sheep. Am J Obstet Gynecol. 2009;200:195.e1-195.e10. 
93. Been JV, Rours IG, Kornelisse RF, Jonkers F, de Krijger RR, Zimmermann LJ. Chorioamnionitis alters the response to surfactant in preterm infants. J Pediatr. 2010;156:10-15.

94. Duran R, Ozbek UV, Ciftdemir NA, Acunaş B, Süt N. The relationship between leukemoid reaction and perinatal morbidity, mortality, and chorioamnionitis in low birth weight infants. Int $J$ Infect Dis. 2010;14(11):e998-1001.

95. Zanardo V, Vedovato S, Trevisanuto DD, et al. Histological chorioamnionitis and neonatal leukemoid reaction in low-birth-weight infants. Hum Pathol. 2006;37(1):87-91.

96. Sweet DG, Carnielli V, Greisen G, et al. European consensus guidelines on the management of respiratory distress syndrome - 2016 update. Neonatology. 2017;111(2):107-125.

97. Hartling L, Liang Y, Lacaze-Masmonteil T. Chorioamnionitis as a risk factor for bronchopulmonary dysplasia: a systematic review and meta-analysis. Arch Dis Child Fetal Neonatal Ed. 2012;97(1): F8-F17.

98. Park HW, Choi YS, Kim KS, Kim SN. Chorioamnionitis and patent ductus arteriosus: a systematic review and meta-analysis. PLoS One. 2015;10(9):e0138114.

99. Behbodi E, Villamor-Martínez E, Degraeuwe PLJ, Villamor E. Chorioamnionitis appears not to be a risk factor for patent ductus arteriosus in preterm infants: a systematic review and meta-analysis. Sci Rep. 2016;6:37967.

100. Eastman NJ, Deleon M. The etiology of cerebral palsy. Am J Obstet Gynecol. 1955;69(5):950-961.

101. Nelson KB, Ellenberg JH. Epidemiology of cerebral palsy. Adv Neurol. 1978; 19:421-435.

102. Nelson KB, Grether JK, Dambrosia JM, et al. Neonatal cytokines and cerebral palsy in very preterm infants. Pediatr Res. 2003;53(4): 600-607.

103. Volpe JJ. Cerebral white matter injury of the premature infant - more common than you think. Pediatrics. 2003;112:176-179.

104. Dyet LE, Kennea N, Counsell SJ, et al. Natural history of brain lesions in extremely preterm infants studied with serial magnetic resonance imaging from birth and neurodevelopmental assessment. Pediatrics. 2006;118:536-548

105. Hack M, Taylor HG, Drotar D, et al. Poor predictive validity of the Bayley Scales of Infant Development for cognitive function of extremely low birth weight children at school age. Pediatrics. 2005;116: 333-341.

106. Wilson-Costello D, Friedman H, Minich N, Fanaroff AA, Hack M. Improved survival rates with increased neurodevelopmental disability for extremely low birth weight infants in the 1990s. Pediatrics. 2005;115(4):997-1003.

107. Khwaja O, Volpe JJ. Pathogenesis of cerebral white matter injury of prematurity. Arch Dis Child Fetal Neonatal Ed. 2008;93(2):F153-F161.

108. Rorke LB. Anatomical features of the developing brain implicated in pathogenesis of hypoxic-ischemic injury. Brain Pathol. 1992;2(3) 211-221.

109. Inage YW, Itoh M, Takashima S. Correlation between cerebrovascular maturity and periventricular leukomalacia. Pediatr Neurol. 2000;22:204-208.

110. Ballabh P, Braun A, Nedergaard M. Anatomic analysis of blood vessels in germinal matrix, cerebral cortex, and white matter in developing infants. Pediatr Res. 2004;56:117-124.

111. Cheranov SY, Jaggar JH. TNF-alpha dilates cerebral arteries via $\mathrm{NAD}(\mathrm{P}) \mathrm{H}$ oxidase-dependent $\mathrm{Ca} 2+$ spark activation. Am J Physiol Cell Physiol. 2006;290:C964-971.

112. Kadhim HJ, Tabarki B, Verellen G, De Prez C, Rona AM, Sébire G. Inflammatory cytokines in the pathogenesis of periventricular leukomalacia. Neurology. 2001;56:1278-1284.
113. Haynes RL, Folkerth RD, Keefe R, et al. Nitrosative and oxidative injury to premyelinating oligodendrocytes is accompanied by microglial activation in periventricular leukomalacia in the human premature infant. J Neuropathol Exp Neurol. 2003;62:441-450.

114. Leviton A, Dammann O, Durum SK. The adaptive immune response in neonatal cerebral white matter damage. Ann Neurol. 2005;58:821-828.

115. Nasef N, Shabaan AE, Schurr P, et al. Effect of clinical and histological chorioamnionitis on the outcome of preterm infants. Am J Perinatol. 2013;30(1):59-68.

116. Shatrov JG, Birch SC, Lam LT, Quinlivan JA, McIntyre S, Mends GL. Chorioamnionitis and cerebral palsy: a meta-analysis. Obstet Gynecol. 2010;116(2 Pt 1):387-392.

117. Suppiej A, Franzoi M, Vedovato S, Marucco A, Chiarelli S, Zanardo V. Neurodevelopmental outcome in preterm histological chorioamnionitis. Early Hum Dev. 2009;85(3):187-189.

118. Pappas A, Kendrick DE, Shankaran S, et al.; Eunice Kennedy Shriver National Institute of Child Health and Human Development Neonatal Research Network. Chorioamnionitis and early childhood outcomes among extremely low-gestational-age neonates. JAMA Pediatr. 2014;168(2):137-147.

119. Wu YW. Systematic review of chorioamnionitis and cerebral palsy. Ment Retard Dev Disabil Res Rev. 2002;8:25-29.

120. Ylijoki M, Lehtonen L, Lind A, et al; PIPARI Study Group. Chorioamnionitis and five-year neurodevelopmental outcome in preterm infants. Neonatology. 2016;110(4):286-295.

121. Ylijoki M, Ekholm E, Haataja L, Lehtonen L; PIPARI study group. Is chorioamnionitis harmful for the brain of preterm infants? A clinical overview. Acta Obstet Gynecol Scand. 2012;91(4):403-419.

122. Shi Z, Ma L, Luo K, et al. Chorioamnionitis in the development of cerebral palsy: a meta-analysis and systematic review. Pediatrics. 2017;139:e20163781.

123. Maisonneuve E, Ancel PY, Foix-L'Hélias L, Marret S, Kayem G. Impact of clinical and/or histological chorioamnionitis on neurodevelopmental outcomes in preterm infants: a literature review. $J$ Gynecol Obstet Hum Reprod. 2017;46(4):307-316.

124. Johnson CB, Jenkins DD, Bentzley JP, et al. Proton magnetic resonance spectroscopy and outcome in term neonates with chorioamnionitis. J Perinatol. 2015;35(12):1030-1036.

125. Hatfield T, Wing DA, Buss C, Head K, Muftuler T, Davis EP. Magnetic resonance imaging demonstrates long-term changes in brain structure in children born preterm and exposed to chorioamnionitis. Am JObstet Gynecol. 2011;205(4):384.e1-8.

126. Elimian A, Verma U, Beneck D, Cipriano R, Visintainer P, Tejani N. Histologic chorioamnionitis, antenatal steroids, and perinatal outcomes. Obstet Gynecol. 2000;96(3):333-336.

127. Lau J, Magee F, Qiu Z, Houbé J, Von Dadelszen P, Lee SK. Chorioamnionitis with a fetal inflammatory response is associated with higher neonatal mortality, morbidity, and resource use than chorioamnionitis displaying a maternal inflammatory response only. Am J Obstet Gynecol. 2005;193(3Pt1):708-713.

128. Kosuge S, Ohkuchi A, Minakami H, et al. Influence of chorioamnionitis on survival and morbidity in singletons live-born at $<32$ weeks of gestation. Acta Obstet Gynecol Scand. 2000;79(10):861-865.

129. Costeloe K, Hennessy E, Gibson AT, Marlow N, Wilkinson AR. The EPICure study: outcomes to discharge from hospital for infants born at the threshold of viability. Pediatrics. 2000;106(4):659-671.

130. Lahra MM, Jeffery HE. A fetal response to chorioamnionitis is associated with early survival after preterm birth. Am J Obstet Gynecol. 2004;190(1):147-151.

131. Mitra S, Aune D, Speer CP, Saugstad OD. Chorioamnionitis as a risk factor for retinopathy of prematurity: a systematic review and metaanalysis. Neonatology. 2014;105:189-199. 


\section{Publish your work in this journal}

Research and Reports in Neonatology is an international, peer-reviewed, open access journal publishing original research, reports, editorials, reviews and commentaries on neonatal health. The manuscript management system is completely online and includes a very quick and fair peer-review system. Visit http://www.dovepress.com/testimonials.php to read real quotes from published authors.

Submit your manuscript here: https://www.dovepress.com/research-and-reports-in-neonatology-journa 